\title{
The efficiency of action of futsal goalkeepers in game situations with varying results of competition
}

\author{
Andrzej Szwarc ${ }^{1 \mathrm{ACDE}}$, Mateusz Oszmaniec ${ }^{2 \mathrm{ABCE}}$ \\ ${ }^{1}$ Gdańsk University of Physical Education and Sport, Poland \\ ${ }^{2}$ Town Hall of Bytów, Poland
}

Authors' Contribution: A - Study design; B - Data collection; C - Statistical analysis; D - Manuscript Preparation; E - Funds Collection

\begin{abstract}
Purpose:

The aim of the study was to expand knowledge of the efficiency of actions from top-level futsal teams. Goalkeepers' activity, effectiveness and reliability were estimated with a view to implementing the objectives of the game in offence and defence and depending on the changing match status.

Material: $\quad$ Data about the game were registered on a self-developed observation sheet. 23 goalkeepers participating in 31 matches of the World and the European Championships and the UEFA Futsal Cup played in the years 2012-2015 were observed. In order to estimate statistically significant differences in goalkeepers' activity in situations of neutral, favorable and unfavorable competition scores, the results were averaged by dividing each of the applied actions in a given match by the number of minutes played during a given competition result. The outcome was the average performance of a goalkeeper in one minute of the match during a given score. The results of the activity scale, depending on the result of the match, were compared with the Kruskal-Wallis test and the post hoc Dunn Bonferroni test and the Jonckheere-Terpstra trend test. Statistical analysis was conducted with a use of the statistical package $R$ and STATISTICA 10.

Results: $\quad$ It was found that actions to gain the playfield with the ball and to prevent a loss of a goal dominated in futsal goalkeepers' both when drawing as well as winning and losing game and that game status does not determine the style of play of the goalkeeper. Only in nine of the 60 types of actions examined significant differences in activity were fund

Conclusions: $\quad$ The unequivocal claim that the current score during the competition determines the style of the futsal goalkeeper's game (the frequency of taking actions in the game characteristic of his position), is unauthorized at this stage of research. The obtained significant differences in his activity in nine types of actions constitute only a small percentage (15\%) of all his skills in the game.

Keywords: notational analysis, match status, activity of actions
\end{abstract}

\section{Introduction}

In a sport team game, a reliable assessment of a player is possible only through repeated observations of his actions in real-life conditions with an opponent of a similar level of sports proficiency, which is carried out with a use of objective research tools [1]. While assessing players' performance, one should primarily take into account those situational variables that determine the complexity of the game situation. The game situation is determined by the time, the place of the player's action and the tasks he needs to implement, other players' skills and the rules of the game, the place and the current result of competition $[2,3]$. The measure of a player's championship lies in his ability to cooperate efficiently and perform various individual actions to achieve a specific goal in the game in increasingly difficult conditions of competition.

For several years, there has been intensive research on futsal players' efficiency of action. A review of the literature [4-7] shows that conceptual eclecticism and a variety of methodological approaches dominate studies of this game. As a rule, research focuses on selected aspects of offensive actions aiming to score goals and position the game (types of attack, ways of scoring goals, set pieces

\footnotetext{
(c) Andrzej Szwarc, Mateusz Oszmaniec, 2021

doi:10.15561/26649837.2021.0204
}

of the game and their effectiveness) and of defensive actions (types of defence, methods and places of receiving the ball). Comprehensive analyses of various variables are rare, and yet an integrated approach that considers multiple aspects is now recognized as crucial in studying sport team games [8].

The game of futsal still remains unknown in many areas, especially in terms of game analysis [5]. This also applies to the position of the goalkeeper. Most analyses focus on the goalkeeper's participation in offensive actions, in situations of outnumbering when each team uses the $5 \mathrm{vs} 4+\mathrm{GK}$ format $[9,10]$, on his efficiency in preventing the loss of a goal and ways of saving shots at the goal $[11,12]$. Comprehensive assessments of the goalkeeper's efficient performance in the game are rare and rather contributory [13]. Therefore, despite a need for systemic approaches to the assessment of football players' performance skills, as regards futsal, firstly, one must accurately describe and define the variables relevant to effective competition [4], primarily in relation to the players' positions [5], and only then estimate their mutual impact on success in the game.

Szwarc et al. [14] and Oszmaniec \& Szwarc [15] already attempted to describe goalkeepers' actions in the game of futsal. They characterized particular actions 
and assessed their efficiency* in terms of offensive and defensive objectives pursued by the goalkeeper, namely: keeping the ball, gaining the playfield with the ball, creating goal-scoring situations, scoring goals and preventing such situations. However, the purpose of this research is to broaden knowledge about the efficiency of futsal goalkeepers of teams of the highest level of sport proficiency in the context of different results of the competition. The following research questions have been formulated: (i) what is the activity, efficiency and reliability of futsal goalkeepers in game situations with a neutral, favorable and unfavorable result? (ii) are there any significant differences in the activity of the top-level futsal goalkeepers in game situations with a neutral, favorable and unfavorable match result?

\section{Material and Methods}

\section{Participants}

23 goalkeepers (age: $27.03 \pm 3.86$ y, body height: $182 \pm 5.64 \mathrm{~cm}$ ) were examined in 31 matches, rendering 62 game analyses in total (Table 1). The examined group comprised players of the highest level of sports proficiency, competing for the World and the European Championship (all matches of the knockout phase, from the quarter-finals to the finals) and for the UEFA Futsal Cup (all matches of the semi-finals and the finals) held in 2012-2015. The study was conducted in a manner that respected the principles established by the Declaration of Helsinki and it was approved by the Ethics Committee of the University.

\section{Measures}

This study used the method of observation. The analysis was made with a use of video footage recorded on a DVD, where during a multiple replay of a game situation the tested action was observed. Data about the game were recorded on a special originally developed observation sheet meeting scientific requirements (the ICC test was used, the intra-rater reliability $-1.00(95 \%$ CI 1.00-1.00) and the inter-rater reliability $-0.99(95 \%$ CI 0.99-1.00) [14].

Activity, effectiveness and reliability of goalkeepers' actions in terms of objectives of the game were investigated. In attacking, the efficiency of actions aiming at keeping the ball, gaining the playfield with the ball, creating goal-scoring situations and scoring a goal were estimated, while in defence, the efficiency of actions against losing a goal and against creating a goalscoring situation was evaluated. Goalkeepers' game was analysed within the regular, 40-minute game time. The analysis excluded the goalkeepers' play time in which they were substituted by players from the field in case of

\footnotetext{
* In praxeological terms [18], efficiency of action is understood as a total of practical qualities of play, which includes: activity (number of actions performed by players of one team during a match), effectiveness (number of positive actions with reference to the game's aims) and reliability (ratio between the number of effective actions and the number of all actions of one type during the game). Other indices of play efficiency encompass rationality (actions cognitively justified), valuableness (value of assessment of action efficiency) and economy (loss-gain ratio).
}

an unfavorable competition result. Activity in action was examined with regard to all actions occurring in the game (Table 2), taking into account the division of the pitch into 2 sectors and 3 zones (Figure 1). Two zones were distinguished in sector A: A1 - the goal area and A2 - the defence area, from the goal line to the centre line of the pitch, excluding the goal area. In sector B, zone A3 was distinguished - the area of the field of attack, from the centre line of the pitch to the end line of the pitch.

\section{Statistical analysis}

In order to estimate statistically significant differences in goalkeepers' activity in situations of neutral, favorable and unfavorable competition scores, the results were averaged by dividing each of the applied actions in a given match by the number of minutes played during a given competition result. The outcome was the average performance of a goalkeeper in one minute of the match during a given score. This procedure was necessary because the examined goalkeepers acted for various lengths of time in situations of neutral, favorable and unfavorable scores. The normality of the distribution of activity results in these situations was analysed with the Shapiro-Wilk test, and after finding significant deviations from the normal distribution, further analyses were carried out with nonparametric methods. The results of the activity scale, depending on the result of the match, were compared with the Kruskal-Wallis test and the post hoc Dunn Bonferroni test and the Jonckheere-Terpstra trend test. Statistical analysis was conducted with a use of the statistical package $R$ and STATISTICA 10.

\section{Results}

The data in Table 3 refer to the competition of goalkeepers from the best futsal teams participating in matches of the knockout phase of the World and European Championships and in the UEFA Futsal Cup in the years 2012-2015. In situations of neutral, favorable and unfavorable score, dominated the actions of gaining the playfield with the ball $(711,560$ and 528 actions, respectively) and of preventing a loss of a goal $(459,424$ and 353 actions, respectively). Goalkeepers most rarely executed actions aimed at scoring a goal $(17,31$ and 20 actions, respectively). The analysed goalkeepers achieved the highest reliability in situations of neutral, favorable and unfavorable scores in actions aimed at keeping the ball and preventing the creation of scoring situations. They failed the most often while scoring a goal. They played the longest in a neutral competition result (974 minutes). During a favorable result, they played for 753 minutes, and in a situation of an unfavorable result for 586 minutes.

A comparison of the averaged results of the studied players' activity in 12 actions of keeping the ball (Table 2 , items 30-41) in the context of three different scores of competition showed that only during keeping the ball by receiving it from a partner in zone A1 (Table 2, item 35) there were significant differences between the frequency of performing this action in game situations with neutral, favorable and unfavorable results. Analysis with a use of the post-hoc Dunn Bonferroni test showed (Table 4) 
Table 1. List of the examined futsal goalkeepers from teams of the highest sports level along with their playing time in situations of a neutral, favorable and unfavorable result of the competition.

\begin{tabular}{|c|c|c|c|c|c|c|c|c|c|}
\hline \multirow[b]{2}{*}{ No. } & \multirow[b]{2}{*}{$\begin{array}{l}\text { National team } \\
\text { or } \\
\text { club (country) }\end{array}$} & \multirow[b]{2}{*}{ Goalkeeper } & \multirow[b]{2}{*}{$\begin{array}{l}\text { Age } \\
\text { [years] }\end{array}$} & \multirow[b]{2}{*}{$\begin{array}{l}\text { Body } \\
\text { height } \\
{[\mathrm{cm}]}\end{array}$} & \multirow[b]{2}{*}{$\begin{array}{l}\text { Number } \\
\text { of } \\
\text { matches } \\
\text { played }\end{array}$} & \multicolumn{4}{|c|}{ Goalkeeper's playing time } \\
\hline & & & & & & $\begin{array}{l}\text { Actual } \\
\text { playing } \\
\text { time } \\
\text { [min' sec] }\end{array}$ & $\begin{array}{l}\text { Neutral } \\
\text { result } \\
\text { [min] }\end{array}$ & $\begin{array}{l}\text { Favorable } \\
\text { result } \\
\text { [min] }\end{array}$ & $\begin{array}{l}\text { Unfavorable } \\
\text { result [min' } \\
\text { sec] }\end{array}$ \\
\hline 1. & Italy & Mammarella & 28 & 176 & 8 & $269^{\prime} 44$ & 100 & 112 & $57^{\prime} 44$ \\
\hline 2. & Russia & Gustavo & 33 & 184 & 6 & $229^{\prime} 51$ & 82 & 96 & $85^{\prime} 08$ \\
\hline & $\begin{array}{l}\text { Marca Futsal } \\
\text { (Italy) }\end{array}$ & & & & & & 86 & 77 & $33^{\prime} 01$ \\
\hline 3. & $\begin{array}{l}\text { Kairat Almaty } \\
\text { (Kazakhstan) }\end{array}$ & Higuita & 26 & 181 & 5 & $196^{\prime} 01$ & & & \\
\hline 4. & Barcelona & Sedano & 33 & 188 & 4 & $151^{\prime} 03$ & 66 & 54 & $30 ’ 03$ \\
\hline 5. & $\begin{array}{l}\text { Sporting CP } \\
\text { (Portugal) }\end{array}$ & Benedito & 34 & 177 & 4 & $146^{\prime} 33$ & 79 & 35 & $32^{\prime} 33$ \\
\hline 6. & $\begin{array}{l}\text { Dinamo Moscow } \\
\text { (Russia) }\end{array}$ & Popov & 32 & 185 & 4 & $142^{\prime} 42$ & 36 & 60 & $46^{\prime} 42$ \\
\hline 7. & Croatia & Jukić & 26 & 190 & 4 & $137 ’ 30$ & 34 & 12 & $96^{\prime} 41$ \\
\hline 8. & Brazil & Tiago & 31 & 173 & 3 & 120 & 62 & 34 & 24 \\
\hline 9. & Spain & Juanjo & 27 & 185 & 3 & 120 & 49 & 64 & 7 \\
\hline 10. & Spain & Amado & 36 & 185 & 3 & $115^{\prime} 12$ & 52 & 62 & $1^{\prime} 12$ \\
\hline 11. & Colombia & Lozano & 30 & 180 & 2 & 80 & 34 & 17 & 29 \\
\hline 12. & Spain & Rafa & 34 & 192 & 2 & $78^{\prime} 18$ & 33 & 35 & $10^{\prime} 18$ \\
\hline 13. & Ukraine & Ivanyak & 30 & 180 & 2 & $78^{\prime} 08$ & 51 & 0 & $27^{\prime} 08$ \\
\hline 14. & Russia & Zuev & 32 & 186 & 2 & $75^{\prime} 45$ & 53 & 6 & $16^{\prime} 45$ \\
\hline 15. & Romania & Lancu & 34 & 180 & 2 & 41 & 14 & 0 & 27 \\
\hline 16. & Argentina & Elias & 29 & 182 & 1 & 40 & 22 & 18 & 0 \\
\hline 17. & Colombia & Nanez & 28 & 180 & 1 & 40 & 28 & 0 & 12 \\
\hline 18. & $\begin{array}{l}\text { Sporting Lisbon } \\
\text { (Portugal) }\end{array}$ & Cristiano & 36 & 170 & 1 & 40 & 13 & 22 & 5 \\
\hline 19. & Serbia & Aksentijević & 29 & 189 & 1 & $37 ; 02$ & 30 & 4 & $3^{\prime} 02$ \\
\hline 20. & Ukraine & Lytvynenko & 27 & 175 & 1 & $37^{\prime} 10$ & 13 & 0 & $24^{\prime} 10$ \\
\hline 21. & Slovenia & Mordej & 24 & 182 & 1 & $35^{\prime} 15$ & 11 & 0 & $24^{\prime} 15$ \\
\hline 22. & $\begin{array}{l}\text { Iberia Star } \\
\text { (Georgia) }\end{array}$ & Celio & 28 & 178 & 1 & $25^{\prime} 51$ & 12 & 0 & $13^{\prime} 51$ \\
\hline 23. & Moscow (Russia) & Trushkin & 21 & 188 & 1 & $35^{\prime} 55$ & 13 & 5 & 7'55 \\
\hline
\end{tabular}

Table 2. Types of analysed actions performed in the game by the examined goalkeepers.

\begin{tabular}{ll}
\hline No. & Type of action \\
\hline 1. & Gaining the playfield by throwing the ball with an underhand swing in zone A1 \\
2. & Gaining the playfield by throwing the ball overhead single-handedly in zone A1 \\
3. & Gaining the playfield by throwing the ball in "another way" - hip throw, two-handed throw in zone A1 \\
4. & Gaining the playfield by a short pass of the ball with a foot after receiving in zone A1 \\
5. & Gaining the playfield by a short pass of the ball with a foot after receiving in zone A2 \\
6. & Gaining the playfield by a short pass of the ball with a foot after receiving in zone A3 \\
7. & Gaining the playfield by a long pass of the ball with a foot after receiving in zone A1 \\
8. & Gaining the playfield by a long pass of the ball with a foot after receiving in zone A2 \\
9. & Gaining the playfield by a short pass of the ball with a foot without receiving in zone A1 \\
10. & Gaining the playfield by a short pass of the ball with a foot without receiving in zone A2 \\
11. Gaining the playfield by a short pass of the ball with a foot without receiving in zone A3 \\
12. Gaining the playfield by a long pass of the ball with a foot without receiving in zone A1
\end{tabular}


Table 2. Continuation

No. Type of action

13. Gaining the playfield by a long pass of the ball with a foot without receiving in zone A2

14. Gaining the playfield by a long pass of the ball with a foot without a pass in zone A3

Gaining the playfield by passing the ball with a foot in "another way", i.e. after intercepting, after faking and/or dribbling the ball, from a set piece in zone A1

Gaining the playfield by passing the ball with a foot in "another way" - after intercepting, after faking and/or dribbling the ball, from a set piece in zone A2

Gaining the playfield by passing the ball with a foot in "another way" - after intercepting, after faking and/or dribbling the ball, from a set piece in zone $A 3$

18. Gaining the playfield by faking and/or dribbling the ball in zone A1

19. Gaining the playfield by faking and/or dribbling the ball in zone $A 2$

20. Gaining the playfield by faking and/or dribbling the ball in zone $A 3$

21. Scoring a goal (in contact or without contact with an opponent) by hitting the ball with a foot in zone A1

22. Scoring a goal (in contact or without contact with an opponent) by hitting the ball with a foot in zone $A 2$

23. Scoring a goal (in contact or without contact with an opponent) by hitting the ball with a foot in zone A3

24. Scoring a goal (in contact or without contact with an opponent) by hitting the ball dropped from a hand in zone A1

25. Creating a goal-scoring situation by throwing the ball overhead single-handedly in zone A1

Creating a goal-scoring situation by throwing the ball with a hand in "another way" - hip throw, two-handed throw in zone $\mathrm{A} 1$

27. Creating a goal-scoring situation by passing the ball with a foot from the ground after receiving in zone $A 1$

28. Creating a goal-scoring situation by passing the ball with a foot from the ground after receiving in zone $A 2$

29. Creating a goal-scoring situation by passing the ball with a foot from the ground after receiving in zone $A 3$

30. Sliding tackle to keep the ball in play in zone A2

31. Keeping the ball by faking and/or dribbling in zone $A 1$

32. Keeping the ball by faking and/or dribbling in zone $A 2$

33. Keeping the ball by catching it after faking and/or dribbling in zone A1

34. Keeping the ball by catching the ball after partner's playing in zone A1

35. Keeping the ball by receiving the ball from a partner in zone A1

36. Keeping the ball by receiving the ball from a partner in zone $A 2$

37. Keeping the ball by receiving the ball from a partner in zone $A 3$

38. Keeping the ball by passing the ball backwards in zone A1

39. Keeping the ball by passing the ball backwards in zone $A 2$

40. Keeping the ball by passing the ball backwards in zone A3

41. Keeping the ball by passing the ball from a set-piece in zone $A 2$

Preventing the loss of a goal by catching the ball (in place, in half-kneeling, in kneeling, in jumping, in robinsonade, in the hurdle sit) in zone $A 1$

43. Preventing the loss of a goal by punching the ball in zone A1

Preventing the loss of a goal by pushing the ball (in place, in half-kneeling, in kneeling, in jumping, in robinsonade, in the hurdle sit) in zone $A 1$

45. Preventing the loss of a goal through defence with legs in zone A1

46. Preventing the loss of a goal through situational defence in zone A1

47. Preventing the loss of a goal through defence in a $1 \times 1$ situation in zone $A 1$

Preventing the loss of a goal by defending a set piece (penalty kick, direct and / or indirect free kick, throwin and corner kick) in zone A1

49. Preventing the loss of a goal through intervention without contact with the ball in zone A1

Preventing the loss of a goal by consequential doubling (catching the ball, situational defence, defence without contact with the ball) in zone A1

Preventing the creation of a goal-scoring situation by catching the ball (in place, in half-kneeling, in kneeling, in jumping, in robinsonade) in zone A1 
Table 2. Continuation

No. Type of action
52. Preventing the creation of a goal-scoring situation by punching the ball in zone A1
53. Preventing the creation of a goal-scoring situation by pushing the ball (in place, in half-kneeling, in kneeling,
in jumping, in robinsonade) in zone A1
54. Preventing the creation of a goal-scoring situation by intercepting / clearing the ball with / without falling to
the ground in zone A1
55. Preventing the creation of a goal-scoring situation by intercepting / clearing the ball with / without falling to
56. Preventing the creation of a goal-scoring situation by intervening without contact with the ball in zone A1
57. Preventing the creation of a goal-scoring situation by intervening without contact with the ball in zone A2
58. Preventing the creation of a goal-scoring situation by intervening without contact with the ball in zone A3
59. Preventing the creation of a goal-scoring situation by consequential doubling (catching the ball, clearing the
60. Preventing the creation of a goal-scoring situation by consequential doubling (catching the ball, clearing the
ball with / without falling to the ground, intervention without contact with the ball) in zone A2

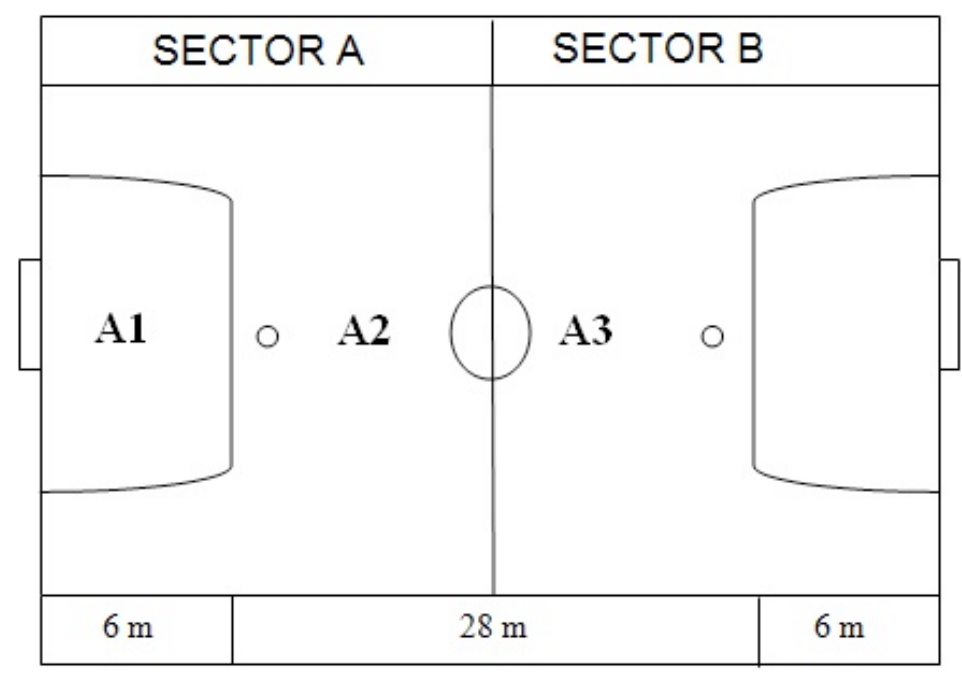

Figure 1. Division of the field into zones and sectors.

Table 3. The efficiency of offensive and defensive actions of the examined goalkeepers in the context of the implemented objectives of the game in situations of different competition results.

\begin{tabular}{|c|c|c|c|c|c|c|c|c|c|}
\hline \multirow{3}{*}{ Type of actions } & \multicolumn{9}{|c|}{ Number of actions } \\
\hline & \multicolumn{3}{|c|}{ Neutral score } & \multicolumn{3}{|c|}{ Favorable score } & \multicolumn{3}{|c|}{ Unfavorable score } \\
\hline & $\mathbf{A}$ & E & $\mathbf{R}$ & A & $\mathbf{E}$ & $\mathbf{R}$ & A & E & $\mathbf{R}$ \\
\hline Keeping the ball & 205 & 197 & 96 & 177 & 173 & 98 & 173 & 168 & 97 \\
\hline Gaining the playfield with the ball & 711 & 632 & 89 & 560 & 475 & 85 & 528 & 474 & 90 \\
\hline Creating goal-scoring situations & 52 & 32 & 62 & 42 & 29 & 69 & 33 & 20 & 61 \\
\hline Scoring a goal & 17 & 0 & 0 & 31 & 4 & 13 & 20 & 1 & 5 \\
\hline Preventing the loss of a goal & 459 & 396 & 86 & 424 & 364 & 86 & 353 & 316 & 90 \\
\hline Preventing the creation of goal-scoring situations & 218 & 209 & 96 & 170 & 166 & 98 & 218 & 205 & 94 \\
\hline $\begin{array}{l}\text { Total playing time of the examined goalkeepers } \\
\text { [min] }\end{array}$ & 974 & & & 753 & & & 586 & & \\
\hline $\begin{array}{l}\text { Match participation rate } \\
\text { [number of full matches] }\end{array}$ & 24.23 & & & 18.55 & & & 14.65 & & \\
\hline
\end{tabular}

A - activity (number of actions), E - efficiency (number of actions), R - reliability (\%) 
Table 4. List of actions in which the activity of the examined goalkeepers significantly differed depending on the competition result.

\begin{tabular}{|c|c|c|c|c|c|c|c|c|c|c|c|c|c|}
\hline \multirow[t]{2}{*}{$\begin{array}{l}\text { No } \\
\text { of } \\
\text { action }^{1}\end{array}$} & \multirow[t]{2}{*}{$\begin{array}{l}\text { Game } \\
\text { status }\end{array}$} & \multirow[t]{2}{*}{$x$} & \multirow[t]{2}{*}{ SD } & \multirow[t]{2}{*}{ Min } & \multirow[t]{2}{*}{$\mathbf{Q}_{1}$} & \multirow[t]{2}{*}{$Q_{2}$} & \multirow[t]{2}{*}{$\mathbf{Q}_{3}$} & \multirow[t]{2}{*}{ Max } & \multirow{2}{*}{$\begin{array}{l}\text { p } \\
\text { Kruskal- } \\
\text { Wallis } \\
\text { test }\end{array}$} & \multirow[t]{2}{*}{$\begin{array}{l}\mathbf{p} \\
\text { (Jonckheere- } \\
\text { Terpstra test) }\end{array}$} & \multicolumn{2}{|c|}{$\begin{array}{l}\text { p } \\
\text { (post-hoc Dunn } \\
\text { Bonferroni test) }\end{array}$} & \multirow[b]{2}{*}{$\mathbf{L}$} \\
\hline & & & & & & & & & & & $\mathbf{W}$ & D & \\
\hline \multirow{3}{*}{1} & $w$ & .17 & .21 & .00 & .00 & .07 & .34 & 1.00 & & & & $.0023 * *$ & .3035 \\
\hline & $\mathrm{D}$ & .30 & .22 & .00 & .17 & .29 & .45 & 1.00 & $.0035^{* *}$ & .0846 & $.0023^{* *}$ & & .2543 \\
\hline & $\mathrm{L}$ & .33 & .62 & .00 & .00 & .17 & .48 & 4.46 & & & .3035 & .2543 & \\
\hline \multirow{3}{*}{22} & w & .01 & .03 & .00 & .00 & .00 & .00 & .17 & & & & $.0406^{*}$ & .0406 \\
\hline & D & .00 & .00 & .00 & .00 & .00 & .00 & .00 & $.0172^{*}$ & $.0135^{*}$ & $.0406^{*}$ & & 1.00 \\
\hline & L & .00 & .00 & .00 & .00 & .00 & .00 & .00 & & & $.0406^{*}$ & 1.00 & \\
\hline \multirow{3}{*}{24} & w & .01 & .03 & .00 & .00 & .00 & .00 & .12 & & & & $.0005^{* * *}$ & .0005 \\
\hline & D & .00 & .00 & .00 & .00 & .00 & .00 & .00 & $.0001^{* * *}$ & $.0002^{* *}$ & $.0005^{* * *}$ & & 1.00 \\
\hline & $\mathrm{L}$ & .00 & .00 & .00 & .00 & .00 & .00 & .00 & & & $.0005^{* * *}$ & 1.00 & \\
\hline \multirow{3}{*}{35} & w & .09 & .14 & .00 & .00 & .00 & .14 & 0.50 & & & & $.0323^{*}$ & 1.00 \\
\hline & $\mathrm{D}$ & .16 & .27 & .00 & .00 & .12 & .20 & 2.00 & $.0133^{*}$ & .9894 & $.0323^{*}$ & & .0331 \\
\hline & L & .09 & .13 & .00 & .00 & .00 & .16 & .48 & & & 1.00 & $.0331^{*}$ & \\
\hline \multirow{3}{*}{42} & w & .07 & .12 & .00 & .00 & .00 & .11 & .50 & & & & .7052 & .5001 \\
\hline & D & .09 & .15 & .00 & .00 & .04 & .11 & 1.00 & $.0365^{*}$ & .1683 & .7052 & & .0305 \\
\hline & $\mathrm{L}$ & .04 & .08 & .00 & .00 & .00 & .07 & .44 & & & .5001 & $.0305^{*}$ & \\
\hline \multirow{3}{*}{44} & w & .12 & .16 & .00 & .00 & .06 & .18 & .80 & & & & .5941 & .6620 \\
\hline & D & .14 & .19 & .00 & .01 & .09 & .18 & 1.00 & $.0426^{*}$ & $.2039^{*}$ & .5941 & & 0.0360 \\
\hline & L & .10 & .19 & .00 & .00 & .00 & .15 & 1.00 & & & .6620 & $.0360^{*}$ & \\
\hline \multirow{3}{*}{45} & w & .05 & .08 & .00 & .00 & .00 & .07 & .32 & & & & .1951 & .8357 \\
\hline & D & .07 & .14 & .00 & .00 & .04 & .09 & 1.00 & $.0125^{*}$ & $.2845^{*}$ & .1951 & & .0102 \\
\hline & $\mathrm{L}$ & .03 & .07 & .00 & .00 & .00 & .04 & .32 & & & .8357 & $.0102^{*}$ & \\
\hline \multirow{3}{*}{55} & w & .02 & .04 & .00 & .00 & .00 & .00 & .20 & & & & $.0288^{*}$ & .1136 \\
\hline & D & .04 & .06 & .00 & .00 & .00 & .07 & .27 & $.0233^{*}$ & $.0344^{*}$ & $.0288^{*}$ & & 1.00 \\
\hline & $\mathrm{L}$ & .06 & .13 & .00 & .00 & .00 & .06 & .66 & & & .1136 & 1.00 & \\
\hline \multirow{3}{*}{56} & w & .02 & .05 & .00 & .00 & .00 & .00 & .25 & & & & .1163 & 1.00 \\
\hline & D & .05 & .14 & .00 & .00 & .00 & .05 & 1.00 & $.0321^{*}$ & .7454 & .1163 & & .0452 \\
\hline & $\mathrm{L}$ & .02 & .07 & .00 & .00 & .00 & .00 & .33 & & & 1.00 & $.0452^{*}$ & \\
\hline
\end{tabular}

1 according to Table 2, W- winning, D- drawing, L- losing, $\mathrm{p}$ - level of significance, $* \mathrm{p} \leq 0.05 * * \mathrm{p} \leq 0.01 * * * p \leq$ 0.001

that the respondents performed this action significantly more often in a game situation with a neutral score than during competition with a favorable or unfavorable score $(p \leq 0.05)$. In the remaining 11 actions of keeping the ball, such differences were not found. On average, goalkeepers were active in this action during one minute of the game, playing in situations of a neutral score (0.16), and slightly less during a favorable or an unfavorable competitive result (0.09).

On the other hand, out of 20 actions of gaining the playfield with the ball (Table 2, items 1-20) only in only action - gaining the playfield by throwing the ball with an underhand swing in zone A1 (Table 2, item 1) - did the players' activity significantly vary depending on different scores. The examined goalkeepers significantly more often $(\mathrm{p} \leq 0.01)$ performed these actions in a game situation with a neutral result than during competition with a favorable score (Table 4). On average, they performed the most actions during one minute of the game when playing in situations of unfavorable scores $(0.33)$, slightly less during neutral situations (0.3), and the least in game situations with favorable scores (0.17).

Of the four types of goal-scoring actions (Table 2, items 21-24), in two (scoring a goal in contact or without contact with an opponent by hitting the ball with a leg in zone A2 and by hitting the ball dropped from the hand in zone A1), statistically significant differences were found in the activity of actions depending on the score. It follows from statistical analysis (Table 4) that goalkeepers performed these actions significantly more often in a game situation with a favorable result than during competition with a neutral or an unfavorable score 
$(p \leq 0.05)$. On average, the most actions during one minute of the match occurred in situations of a favorable score $(0.01)$; these actions were not used in game situations with neutral and unfavorable scores.

A comparison of the average results of the examined players' activity in 9 actions against the loss of a goal in the context of three different results of competition showed (Table 2, items 42-50) that while preventing the loss of a goal, i.e. while catching the ball - in place, in halfkneeling, in kneeing, in jumping, in robinsonade, in the hurdle sit in zone A1 (Table 2, item 42), while pushing the ball - in place, in half-kneeling, in kneeing, in jumping, in robinsonade, in the hurdle sit in zone A1 (Table 2, item 44) and while defending the ball with legs in zone A1 (Table 2 , item 45), there were significant differences between the frequency of performing these actions by the examined players in game situations with neutral, favorable and unfavorable results. According to the data presented in Table 4, goalkeepers performed these three actions significantly more often in game situations with a neutral result than in those with an unfavorable score $(\mathrm{p} \leq 0.05)$. In the remaining six actions against losing a goal (Table 2, items 43, 46-50), there were no statistically significant differences in the frequency of performing these actions. On average, during one minute of the match, goalkeepers most often caught the ball playing in situations of a neutral score (0.9), slightly less in favorable ones (0.7), and the least in situation of a unfavorable score in the competition (0.4). When pushing the ball, this was respectively: 0.14 , 0.12 and 0.1 , and when defending the goal with legs: 0.07 , 0.05 and 0.03 , respectively.

On the other hand, a comparison of the average results of the examined players in 10 actions against creating goalscoring situations (Table 2, items 51-60) in the context of three different scores showed that when preventing the creation of goal-scoring situations, i.e. while intercepting / clearing the ball with/without falling to the ground in zone A2 (Table 2, item 55) and defence / intervention without contact with the ball in zone A1 (Table 2, item 56) there were significant differences in the frequency of performing these actions in game situations with neutral, favorable and unfavorable scores. Analysis of the data in Table 4 shows that in preventing the creation of goalscoring situations by intercepting / clearing the ball with/ without falling to the ground in zone A2, goalkeepers performed these actions significantly more often in game situations with a neutral score than when playing with a favorable score $(\mathrm{p} \leq 0.05)$, and in preventing the creation of goal-scoring situations through defence / intervention without contact with the ball in zone A1 significantly more often in game situations with a neutral result than with an unfavorable one $(\mathrm{p} \leq 0.05)$. In the former case, on average, during one minute of the match, they performed the most actions in situations of an unfavorable score (0.06), slightly less when the score was neutral (0.04), and the least in situations of a favorable competition result (0.02), while in the latter case, they performed the most actions when playing in situations of a neutral result (0.05), and slightly less when the competition result was favorable or unfavorable (0.02). In the remaining 8 actions against creating goal-scoring situations (Table 2, items 52-54 and 57-60) no statistically significant differences were found in the frequency of these actions depending on the game result.

\section{Discussion}

The purpose of this study was to broaden knowledge about the efficiency of futsal goalkeepers from teams of the highest level of sport proficiency in the context of the variable of playing in situations with varying results of the competition and about goalkeepers' activity during competition with neutral, favorable and unfavorable scores.

Our research shows (Table 3) that futsal goalkeepers are more often involved in offensive than defensive actions ( $58 \%$ and $42 \%$, respectively), but slightly more often in game situations with a neutral result $(59 \%$ and $41 \%)$ than while playing with a favorable score $(58 \%$ and $42 \%)$ or an unfavorable one ( $57 \%$ and $43 \%$ ). These general trends are also confirmed in 11-player soccer, where there are even three times more offensive than defensive actions $[16,17]$. When attacking, futsal goalkeepers usually use actions aimed to gain the playfield with the ball and to keep the ball $(41 \%$ and $13 \%$ of all actions performed in the game, respectively) in both neutral, favorable and unfavorable results. They perform these actions with very high reliability ( $88 \%$ and $97 \%$, respectively). In turn, they create scoring situations a lot less often. This offensive action accounted for $3 \%$ of all actions performed in the game and was most often performed in game situations with a neutral score. In contrast, scoring goals was performed the least often ( $1.5 \%$ of all actions), and it was the most unreliable ( $7 \%$ reliability) in the game of futsal goalkeepers. In total, in all matches they made only 68 shots at the goal, and the most often they shot at the opponents' goal in game situations with a favorable result (31 actions with 13\% reliability), and the least often with a neutral score (17 shots, all ineffective). It is worth adding that our study corresponds with reports by Kunze et al. [12], who also found $40 \%$ activity in Brazilian futsal goalkeepers' actions aiming to gain the playfield, by and Paz-Franco et al. [13], who proved that gaining the playfield by a passing the ball with a foot or hand dominates offensive actions of goalkeepers of the best Spanish teams. Szwarc et al. [16] also found a similar structure of the efficiency of offensive actions among goalkeepers of 11-person teams.

In defence, the examined goalkeepers more than twice more often prevented the loss of a goal than they acted against creating a goal-scoring situation (Table 3 ), respectively, in situations of a neutral, favorable and unfavorable score: $68 \%$ and $32 \%, 71 \%$ and $29 \%$ and $61 \%$ and $39 \%$. They were the most active in the game with a neutral result (459 actions), and the number of their actions when the score of the game was favorable was $16 \%$ higher than the number of actions taken when the score was unfavorable (424 and 353 actions, respectively). Our results find confirmation in research on 
goalkeepers in 11-player teams. Szwarc et al. [18] noted that goalkeepers' activity in matches concluded in a draw was significantly higher than in won or lost matches, and Taylor et al. [19], Lago-Peñas \& Dellal [20], Castellano et al. [21] and Gómez et al. [22] proved that players of teams with an unfavorable score strive to change the status of the result, usually by attacking more often, thus forcing more activity in defensive actions from players and goalkeepers of the team holding the favorable score.

In this study, sixty actions of goalkeepers in the context of a neutral, favorable and unfavorable competition result were statistically analysed (Table 2). It was proved that only in nine of them they achieve statistically significant differences. In attack, the subjects achieved the highest level of statistically significant differences when scoring a goal in contact or without contact with the opponent by hitting the ball dropped from their hand in zone A1 and by hitting the ball from the ground in zone A2, when they performed these actions significantly more often in game situations with a favorable score than during competition with a neutral and unfavorable result $(p \leq 0.001$ and $p \leq 0.05$, respectively). Still, they performed these actions sporadically (Table 4). These situations most often occurred when the "losing" team was building a positional attack using the goalkeeper on the opponent's half or played without him using the $5 \mathrm{vs} 4+\mathrm{GK}$ format [11, 12], and upon taking possession of the ball the goalkeeper of the "winning" team immediately tried to score a goal. In principle, such actions do not occur in the game of goalkeepers from 11-person teams [17, 23, 24].

The examined goalkeepers playing in a situation of a neutral score applied actions to keep the ball by receiving it from a partner in zone A1 significantly more often than during a favorable or an unfavorable score $(\mathrm{p} \leq 0.05)$. Analysing the game in 11-player soccer, it was proved [25] that the teams tying at the given moment focus on defensive actions on their own half of the pitch, and this causes an increase in their goalkeepers' involvement in positioning the game. Similar behaviors occur in futsal teams in game situations with a neutral score - their goalkeepers also more often receive and play the ball from their own penalty area, without taking excessive risk in the defensive game.

Similar conclusions can be drawn from the analysis of gaining the playfield with the ball. The examined players gained it by throwing the ball with an underhand swing in zone A1 significantly more often in game situations with a neutral result than in those with a favorable result $(\mathrm{p} \leq 0.01)$. This is due to using a positional attack (game without excessive risk) with the goalkeeper's help more frequently. However, no significant differences were found in positioning the game involving the goalkeeper in zones A2 and A3. This is seemingly surprising, especially as regards the unfavorable outcome of the game. After all, teams in these situations are forced by rivals to attack positionally [9], also with the goalkeeper's participation [10], and this means their significant involvement in the actions of gaining the playfield with the ball. Yet, it should be remembered that in consistence with the methodology adopted in this research, the analysis excluded the game time in which the goalkeeper was replaced by another player in situations of an unfavorable score. From among the examined goalkeepers only Higuita (Marca Futsal, Kairat Atmaty) regularly participated in building a positional attack on the opponent's half in the $5 \mathrm{vv} 4+\mathrm{GK}$ situation, hence this explains the results obtained in this study.

In turn, in three out of nine defensive actions (Table 2), i.e. preventing the loss of a goal in zone A1 by: catching the ball, pushing the ball out and defending the goal with legs, the examined goalkeepers significantly more often used these methods of defending the goal in game situations with a neutral result than during competition with an unfavorable one $(\mathrm{p} \leq 0.05)$. The obtained results show that the goalkeepers of the "losing" teams significantly less often prevented the loss of a goal. This should be explained by the fact that players of "losing" teams usually strive to change the status of the game, they attack more often, and thus, their goalkeeper' involvement in defence is much smaller. Such a strategy, the so-called "offensive" defensive has been confirmed by many researchers with respect to 11-player soccer [among others, 26, 27, 28].

In two of the ten actions against creating goalscoring situations, the examined futsal goalkeepers were significantly more active in situations of varying scores (Table 2). In actions preventing scoring a goal by intercepting / clearing the ball with / without falling to the ground in zone A2, they significantly differed in activity in a game situation with a neutral and favorable result $(\mathrm{p} \leq 0.05)$, and in preventing scoring a goal by defence / intervention without contact with the ball in zone A1 in a game situation with a neutral and unfavorable result $(p \leq 0.05)$. In the first case, interpretation of the results for actions against the loss of a goal can also be used to explain the results of this study, but in the second case, unequivocal explanation is difficult to provide. After all, teams playing in situations of an unfavorable score attack more often, and hence their goalkeepers are less often involved in defensive game in their own goal area. This issue requires clarification in subsequent studies.

\section{Conclusion}

The unequivocal claim that the current score during the competition determines the style of the futsal goalkeeper's game, i.e. the frequency of taking actions in the game characteristic of his position, is unauthorized at this stage of research, as the obtained significant differences in his activity in nine types of actions constitute only a small percentage $(15 \%)$ of all his skills in the game. Therefore, research on his activity in game situations with neutral, favorable and unfavorable results should be continued.

\section{Acknowledgements}

The authors thank the financial support by Gdansk University of Physical Education and Sport.

\section{Conflict of interests}

No potential conflict of interest was reported by the authors. 
1. O'Donoghue P. Research methods for sports performance analysis. London: Routledge; 2010. https://doi.org/10.4324/9780203878309

2. Lepschy $H$, Wäsche $H$, Woll A. How to be successful in football: a systematic review. The Open Sports Sciences Journal. 2018; 11: 3-23. https://doi.org/10.2174/1875399X01811010003

3. Sarmento H, Clemente FM, Araújo D, Davids K, Mc Robert A, Figueiredo A. What performance analysts need to know about research trends in association football (2012-2016): a systematic review. Sports Medicine, 2018; 48: 799-836. https://doi.org/ 10.1007/s40279-017-0836-6

4. Moore R, Bullough S, Goldsmith S, Edmondson L. A systematic review of futsal literature. American Journal of Sports Science \& Medicine, 2014; 2(3): 108-116. https://doi.org/10.12691/ajssm-2-3-8

5. Agras H, Ferragut C, Abraldes JA. Match analysis in futsal: a systematic review. International Journal of Performance Analysis in Sport, 2016; 16(2): 652-686. https://doi.org/10.1080/24748668.2016.11868915

6. Sarmento H, Bradley P, Anguera MT, Polido T, Resende R, Campaniço J. Quantifying the offensive sequences that result in goals in elite futsal matches. Journal of Sports Sciences, 2016; 34(7): 621-629. https://doi.org/10.1080/02640414.2015.1066024

7. Méndez C, Gonçalves B, Santos J, Ribeiro JN, Travassos B. Attacking profiles of the best ranked teams from elite futsal leagues. Frontiers in Psychology, 2019; 10(1370): 1-12. https://doi.org/10.3389/fpsyg.2019.01370

8. Ăvila-Moreno FM, Chirosa-Rios LJ, Ureňa-Espá A, LozanoJarque D, Ulloa-Diaz D. Evaluation of tactical performance in invasionteamsports:asystematicreview.InternationalJournal of Performance Analysis in Sport, 2018; 18(2): 195-216. https://doi.org/10.1080/24748668.2018.1460054

9. Vicente-Vila P, Lago-Peñas C. The goalkeeper influence on ball possession effectiveness in futsal. Journal of Human Kinetics, 2016; 51(1): 217-224. https://doi.org/10.1515/hukin-2015-0185

10.Méndez-Domínguez C, Gómez-Ruano MA, RúizPérez LM, Travassos B. Goals scored and received in 5vs4 GK game strategy are constrained by critical moment and situational variables in elite futsal. Journal of Sports Sciences, 2019; 37(21): 2443-2451. https://doi.org/10.1080/02640414.2019.1640567

11.Leite W. Analysis of offensive process of the Portuguese futsal team. Pamukkale Journal of Sport Sciences, 2012;3(3): 78-89. https://dergipark.org.tr/en/pub/psbd/issue/20578/219244

12.Kunze A, Schlosser MW, Brancher EA. Analysis of the most used techniques goalkeeper during the men's futsal games. Revista Brasileira de Futsal e Futebol, 2016; 8(30): 228-234.

13.Paz-Franco A, Bores Cerezal A, Barcala Furelos R, Mecias Calvo M. Analysis of the conducts of elite futsal goalkeeper in the different situations of the game. American Journal of Sports Science \& Medicine, 2014; 2(3): 71-76. https://doi.org/10.12691/ajssm-2-3-1

14. Szwarc A, Oszmaniec M, Lipinska P. The method of goalkeeper's evaluation in futsal. Baltic Journal of Health \& Physical Activity, 2014; 6(2): 100-113. https://doi.org/10.2478/bjha-2014-0010

15.Oszmaniec M, Szwarc A. The efficiency of actions of goalkeepers from sports effective teams in a game of futsal in matches of the final tournament of the World and European Championships in 2012. Baltic Journal of Health \& Physical Activity, 2015; 7(4): 15-27. https://doi.org/10.13140/RG.2.1.2265.1281

16.Szwarc A, Lipińska P, Chamera M. The efficiency model of goalkeeper's actions in soccer. Baltic Journal of Health \& Physical Activity, 2010; 2(2): 132-138. https://doi.org/10.2478/v10131-0013-x

17.Liu H, Gómez MA, Lago-Peñas C. Match Performance Profiles of Goalkeepers of Elite Football Teams. International Journal of Sports Science \& Coaching, 2015; 10(4): 669-682. https://doi.org/1260/1747-9541.10.4.669

18.Szwarc A, Jaszczur-Nowicki J, Aschenbrenner P, Zasada M, Padulo J, Lipinska P. Motion analysis of elite Polish soccer goalkeepers throughout a season. Biology of Sport, 2019; 36(4): 357-363. https://doi.org/10.5114/biolsport.2019.88758

19. Taylor JB, Mellalieu SD, James N, Shearer DA. The influence of match location, quality of opposition, and match status on technical performance in professional association football. Journal of Sports Sciences, 2008; 26(9): 885-895. https://doi.org/ 10.1080/02640410701836887

20.Lago-Peñas $\mathrm{C}$, Dellal A. Ball possession strategies in elite soccer according to the evolution of the match-score: the influence of situational variables. Journal of Human Kinetics, 2010; 25: 93-100. https://doi.org/10.2478/v10078-010-0036-z

21.Castellano J, Casamichana D, Lago-Peñas C. The use of match statistics that discriminate between successful and unsuccessful soccer teams. Journal of Human Kinetics, 2012; 31(1): 139-147. https://doi.org/10.2478/v10078-012-0015-7

22.Gómez MA, Reus M, Parmar N, Travossos B. Exploring elite soccer teams' performances during different match-status periods of close matches' comebacks. Chaos, Solitons \& Fractals, 2020; 132: 109566. https://doi.org/ 10.1016/j.chaos.2019.109566

23.Di Salvo V, Benito PJ, Calderon FJ, Di Salvo M, Pigozzi F. Activity profile of elite goalkeepers during football matchplay. Journal of Sports Medicine and Physical Fitness, 2008: 48(4), 443-446.

24.Sainz de Baranda P, Ortega E, Palao JM. Analysis of goalkeepers' defence in the World Cup in Korea and Japan in 2002. European Journalof Sport Science, 2008; 8(3): 127-134. https://doi.org/10.1080/17461390801919045

25.Almeida C, Ferreira AP, Volossovitch A. Effects of match location, match status and quality of opposition on regaining possession in UEFA champions league. Journal of Human Kinetics, 2014; 41(1): 203-2014. https://doi.org/10.2478/ hukin-2014-0048

26.Lago-Ballesteros J, Lago-Peńas C, Rey E. The effect of playing tactics and situational variables on achieving score-box possessions in a professional soccer team. Journal of Sports Sciences, 2012; 30(14): 1455-1461. https://doi.org/10.1080/02640414.2012.712715

27.Bradley P, Lago-Peńas C, Rey E, Sampaio J. The influence of situational variables on ball possession in the English Premier League. Journal of Sports Sciences, 2014; 32(20): 1867-1873. https://doi.org/10.1080/02640414.2014.887850

28.Santos P, Lago-Peñas C, García-García O. The influence of situational variables on defensive positioning in professional soccer. International Journal of Performance Analysis in Sport, 2017; 17(3): 212-219. https://doi.org/10.1080/24748668.2017.1331571 


\section{Information about the authors:}

Andrzej Szwarc; (Corresponding author); https://orcid.org/0000-0003-1959-3902; andrzej.szwarc@awf.gda.pl; Gdansk University of Physical Education and Sport ; Kazimierza Górskiego 1, 80-336 Gdańsk, Poland.

Mateusz Oszmaniec; https://orcid.org/0000-0002-4317-0478; mateuszoszman@op.pl;Town Hall of Bytów; 1 Maja 15, 77-100 Bytów, Poland..

Cite this article as:

Szwarc A, Oszmaniec M. The efficiency of action of futsal goalkeepers in game situations with varying results of competition. Pedagogy of Physical Culture and Sports, 2021;25(2):98-107. https://doi.org/10.15561/26649837.2021.0204

This is an Open Access article distributed under the terms of the Creative Commons Attribution License, which permits unrestricted use, distribution, and reproduction in any medium, provided the original work is properly cited (http://creativecommons.org/licenses/by/4.0/deed.en).

Received: 10.07.2020

Accepted: 25.08.2020; Published: 30.04.2021 